IN brief

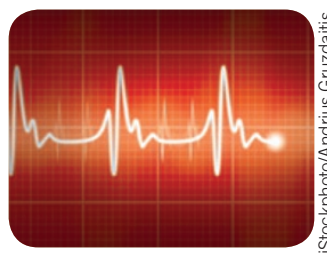

Amylin's diabetes shock

In a major setback for Amylin, the US Food and Drug Administration called for

Fears over long QT.

further tests on Amylin's Bydureon, a onceweekly drug for type 2 diabetes. On October 19, the San Diego-based biotech Amylin, and partner Eli Lilly of Indianapolis, announced that the agency had issued a Complete Response Letter calling for a study known as thorough QT to further investigate the potential effect of the drug's cardiac effects. Bydureon is a longacting formulation of Amylin's approved drug Byetta (exenatide), an analog of the insulinboosting glucagon-like peptide 1 (GLP-1) (Nat. Biotechnol. 28, 109, 2010). Both contain exenatide, but Bydureon contains a higher concentration of the active agent, delivered into the blood by controlled release. The first-in-class synthetic gut hormone drug Byetta generated $\$ 677$ million in 2009 in the US alone. But Bydureon's formulation-once weekly injections compared with twice a day-is predicted to gain competitive edge over its predecessor if approved. Simos Simeonidis, managing director and senior biotech analyst at Rodman \& Renshaw in New York, says that Bydureon had "blockbuster" potential and could have brought in at least $\$ 1$ billion per year for Amylin after the first few years. The FDA's concerns over supratherapeutic concentrations of exenatide may have been triggered by observations in a Byetta study, in which a few patients with blood levels of $500 \mathrm{pg} / \mathrm{ml}$ had lengthened QT intervals. In patients with kidney problems, once-weekly Bydureon can reach five times the normal $200 \mathrm{pg} / \mathrm{ml}$ seen with Byetta. Given the delay in approving Bydureon, alternate treatments for type 2 diabetes like Victoza (liraglutide) from Novo Nordisk, of Princeton, New Jersey, and Amylin's own Byetta, are now expected to flourish. London-based GlaxoSmithKline's investigational Syncria(R) (albiglutide), also a GLP-1 analog, is currently undergoing phase 3 clinical trials. "They were considerably behind," says Yaron Werber, senior biotech analyst at Citigroup in New York. "But now I think they have a chance to close a big part of the gap." Nidhi Subbaraman

\title{
IN their words
}

“At this juncture, I don't know that individuals will have all that much to gain from publishing their data, but I think that Genomes Unzipped will help to prove that there's not all that much to lose, either." Linda Avey, cofounder of 23andMe, comments on a move by 11 Britishbased scientists and a US lawyer to make their own genetic tests publicly available in the hope of encouraging others to share their genome information. (The Times, 11 October 2010)

Table 1 Vaccine mergers \& acquisitions

\begin{tabular}{|c|c|c|c|}
\hline Acquirer & Target (location) & Value & Year \\
\hline Berna Biotech & Rhein Biotech & $\$ 257$ million & 2002 \\
\hline Crucell & Berna Biotech & $\$ 449$ million & 2005 \\
\hline Crucell & SBL Vaccin & $\$ 52$ million & 2006 \\
\hline GlaxoSmithKline & ID Biomedical (Vancouver, Canada) & $\$ 1.4$ billion & 2005 \\
\hline GlaxoSmithKline & Corixa (Seattle) & $\$ 300$ million & 2005 \\
\hline Intercell & Iomai (Gaithersburg, Maryland) & $\$ 189$ million & 2008 \\
\hline Novartis & Chiron (Emeryville, California) & $\$ 5.4$ billion $^{a}$ & 2005 \\
\hline Sanofi Pasteur & Acambis & $\$ 549$ million & 2008 \\
\hline Sanofi Pasteur & Shantha Biotechnics & $\$ 781$ million $^{b}$ & 2009 \\
\hline Sanofi Pasteur & VaxDesign (Orlando, Florida) & $\$ 55$ million $^{\mathrm{c}}$ & 2010 \\
\hline
\end{tabular}

aThe transaction involved the remaining $58 \%$ of Chiron's stock not already held by Novartis. ${ }^{\text {b}}$ Total valuation of the company implied by the terms of the deal. Sanofi Pasteur acquired an $80 \%$ stake. ${ }^{C}$ The deal includes $\$ 5$ million in potential milestone payments.

unit, just as it has with several earlier acquisitions, such as antiviral drug developer Tibotec of Antwerp, Belgium, and antibody developer Centocor located in Horsham, Pennsylvania.

J\&J's imminent acquisition of Crucell is further evidence that the vaccines area, although small in the context of overall pharma sales, is firmly back on the industry's agenda, after a couple of decades during which it had fallen out of favor. Other acquisitions where vaccines have featured prominently (though not exclusively) are Pfizer's takeover of Wyeth and Londonbased AstraZeneca's $\$ 15.2$ billion acquisition of Gaithersburg, Maryland-based MedImmune.

The vaccines market's steady growth equilibrium is punctuated by irregular spurts caused by significant new product introductions. For instance, Wyeth's Prevnar (pneumococcal 7-valent conjugate) or Gardasil (human papillomavirus quadrivalent (types 6, 11, 16 and 18) recombinant vaccine) from Merck of Whitehouse Station, New Jersey, quickly added substantial chunks of revenue to the industry total.

The complexities of manufacturing, combined with the economies of large-scale production, have conspired to make the sector strongly oligopolistic, with the market dominated by a small number of firms. The top five players, Sanofi Pasteur, GSK Biologicals, Merck, Pfizer and Novartis, control around $85 \%$ of the market, with around $\$ 18$ billion of sales in 2009, according to market analysts VacZine Analytics, of Bishop's Stortford, UK. "The industry last year grew by about 9, 10\% over the previous year," says VacZine Analytics director John Savopoulos. By his reckoning Crucell's 2009 vaccine sales of $€ 304$ million (\$424.3 million) would rank the company in ninth place, behind CSL, of Parkville, Australia, and London-based AstraZeneca's MedImmune unit. The H1N1 influenza pandemic had the biggest impact on sales in 2009, bringing in around $\$ 3.5$ billion in additional revenue. In the first three-quarters of 2010 , the top five companies posted combined sales of $\$ 16.9$ billion, excluding the contribution of Sanofi Pasteur MSD, a European joint venture between Sanofi Pasteur and Merck.

Nevertheless, the industry's pipeline remains widely distributed. "Seventy companies are now targeting 40 plus pathogens," Savopoulos says. Some 160 vaccines are in clinical development, around 100 of which are in phase 1 trials. Crucell has the industry's fifth largest pipeline, he notes. It has clinical-stage programs in yellow fever, tuberculosis (TB), malaria, HIV, Ebola virus and Marburg virus as well as preclinical efforts in seasonal influenza, respiratory syncytial virus and in the development of a universal flu vaccine. Only GSK Biologicals, Sanofi Pasteur, Novartis and Merck have more vaccine programs in the clinic. "They look reasonably well positioned. The problem is when you probability-adjust their pipeline-malaria, TB-they're tough areas to be in," Savopoulos says. A preclinical antibody development program, which targets both seasonal and pandemic flu strains, and has attracted $\$ 40.7$ million in US National Institutes' of Health funding (with potentially \$28.4 million more to come), was the main focus of J\&J's 2009 alliance with Crucell. “That technology, if it can be harnessed for an active vaccine, that's a quantum leap above the existing flu market," Savopoulos points out. Jan Van den Bossche identifies a combination monoclonal antibody development program for treating individuals exposed to rabies infection as particularly promising. "It's a clear, understandable program," he says. The program, in phase 2 trials, aims to replace an existing equine immunoglobulin therapy.

Although J\&J will seek further growth from Crucell's existing product portfolio, J\&J's real measure of success will be in the extent to which it can convert pipeline promise into commercial reality. Sanofi Pasteur 'turbocharged' Acambis's ChimeriVax platform when it acquired the Cambridge, UK-based firm, says Savopoulos. "The question is, can J\&J do the same thing?”

Cormac Sheridan, Dublin 